\title{
Plug-Based Microfluidics with Defined Surface Chemistry to Miniaturize and Control Aggregation of Amyloidogenic Peptides ${ }^{* *}$
}

\author{
Matthias Meier, \\ Department of Chemistry, University of Chicago, 929 East 57th Street, Chicago, IL 60637 (USA) \\ Julia Kennedy-Darling, \\ Department of Chemistry, University of Chicago, 929 East 57th Street, Chicago, IL 60637 (USA) \\ Se Hoon Choi, \\ The Center for Molecular Neurobiology, University of Chicago, 947 E 58th Street, Chicago, IL 60637 \\ (USA) \\ Eric M. Norstrom, \\ The Center for Molecular Neurobiology, University of Chicago, 947 E 58th Street, Chicago, IL 60637 \\ (USA) \\ Sangram S. Sisodia, and \\ The Center for Molecular Neurobiology, University of Chicago, 947 E 58th Street, Chicago, IL 60637 \\ (USA) \\ Rustem F. Ismagilov* \\ Department of Chemistry, University of Chicago, 929 East 57th Street, Chicago, IL 60637 (USA)
}

\section{Keywords}

aggregation; Alzheimer's disease; interfaces; microfluidics; proteins

\begin{abstract}
We present a microfluidic method that uses control of interfacial chemistry in nanoliter droplets to enable miniaturized in vitro measurements of protein aggregation. Measuring aggregation of proteins experimentally is fundamental to understanding the biophysics of amyloidosis[1, 2] and for developing methods for detection and treatment of amyloid diseases.[3] In traditional in vitro aggregation experiments, adsorption of amyloid peptides at the air/water[4] and solid/ water[5,6] interfaces accelerates peptide aggregation by enhancing nucleation. Intrinsic stochasticity of nucleation phenomena[7] implies that obtaining statistically significant data often requires multiple experiments performed in parallel, and this makes miniaturization of these experiments attractive. The interfacial effects, however, become even more pronounced on miniaturization of aggregation experiments, as miniaturization increases the surface-tovolume ratio. Miniaturization of aggregation experiments is especially desirable for samples available only in small volumes, such as cerebrospinal fluid (CSF) from mice. The CSF is known to contain components that inhibit formation of amyloid aggregates, and the balance of inhibitory and pro-aggregation activities changes with aging and progression of disease. [8-10] Therefore, CSF and interstitial brain fluid[11] are increasingly interesting for biomarker
\end{abstract}

\footnotetext{
** This research was supported by the National Institutes of Health NIBIB EB000557 and the NIH Director's Pioneer Award DP1 OD003584 to R.F.I. and by Cure Alzheimer's Fund and NIH AG027854 to S.S.S. R.F.I. is a Camille Dreyfus Teacher-Scholar. M.M. was supported by the Alexander von Humboldt Society and J.K.-D. by the NIH Roadmap training program T90 DK070076. We thank Dr. A. M. Seddon and Dr. E. Chan for preliminary experiments and E. W. Haney for editing this manuscript.

Fax: (+1) 773-834-3544, E-mail: E-mail: r-ismagilov@uchicago.edu, Homepage: http://ismagilovlab.uchicago.edu.
} 
discovery and monitoring effects of drugs in animal models of Alzheimer's diseases. Such panels of experiments are not easily done with standard well-plate in vitro assays that require tens of microliters of sample, given that the volume of CSF from a single mouse is only a few microliters. Here we show how such experiments can be performed by using a microfluidic system.

To miniaturize aggregation experiments while controlling the interfacial chemistry, we used a plug-based microfluidic approach[12] in polydimethylsiloxane (PDMS)[13] microfluidic devices modified with teflon tubing.[14] Plugs are nanoliter fluorocarbon-surrounded aqueous droplets formed in the flow of immiscible fluids inside microfluidic channels. To test this approach, we used an exceptionally well characterized amyloid beta peptide, namely, $A \beta_{40}$. Once $A \beta_{40}$ is encapsulated inside a plug, it is protected from the surfaces of microchannels by a layer of fluorocarbon, and the surface chemistry of the aqueous/fluorous interface, rather than aqueous/channel interface, becomes important. To test whether adsorption of $\mathrm{A} \beta_{40}$ at the aqueous/fluorous interface can be minimized, we compared the behavior of $A \beta_{40}$ labeled with HiLyte-488 at the $\mathrm{N}$ terminus at two liquid/liquid interfaces: 1) aqueous peptide/fluorocarbon interface and 2) aqueous peptide $/ \mathrm{R}_{\mathrm{f}}-\mathrm{OEG}_{3}$-protected fluorocarbon interface, where $\mathrm{R}_{\mathrm{f}}-\mathrm{OEG}_{3}$ is an amphiphilic fluorinated surfactant (see Supporting Information) that is added to the carrier fluid, assembles spontaneously at the aqueous/fluorous interface, presents triethylene glycol groups to the aqueous phase, and thereby prevents protein adsorption.[15] In plugs with the fluorocarbon/water interface, an increase in the fluorescence signal of the labeled $\mathrm{A} \beta_{40}$ peptide at the plug edges indicated adsorption of the peptide at the interface $2 \mathrm{~h}$ after encapsulation (Figure $1 \mathrm{~b}$ ). In contrast, in plugs with an $\mathrm{R}_{\mathrm{f}}-\mathrm{OEG}_{3} /$ water interface, the fluorescence signal of the labeled peptide was evenly distributed (Figure $1 \mathrm{c}$ ), that is, $\mathrm{R}_{\mathrm{f}}-\mathrm{OEG}_{3}$ prevents $\mathrm{A} \beta_{40}$ adsorption at the interface. The effectiveness of $\mathrm{R}_{\mathrm{f}}-\mathrm{OEG}_{3}$ is a function of its concentration in the carrier fluid (see Supporting Information). Because prior to encapsulation of $A \beta_{40}$ in plugs, the peptide is exposed to the walls of the channels, we inserted teflon tubing[14] into the $A \beta$ inlet. To confirm that $A \beta_{40}$ was not lost during the encapsulation process, we measured the fluorescence intensity of a series of plugs protected with $\mathrm{R}_{\mathrm{f}}-\mathrm{OEG}_{3}$ containing between 5 and $40 \mu_{\mathrm{m}}$ fluorescein-labeled $\mathrm{A} \beta_{40}$ after encapsulation. We found a linear increase in intensity that coincided with the increase of intensity of fluorescein (combined $R^{2}=0.99$ ), a compound that is not significantly adsorbed on surfaces in our devices (Figure S1, Supporting Information).

Having established the inertness of the plug/fluorocarbon interface to peptide adsorption, we monitored the differences in the aggregation kinetics of $A \beta_{40}$ in plugs with and without $R_{f^{-}}$ $\mathrm{OEG}_{3}$ by using Thioflavin $\mathrm{T}$ (ThT), a dye widely used to monitor aggregation, and observing the increase in the fluorescence of ThT on binding to amyloid aggregates.[16] The aggregation kinetics of $\mathrm{A} \beta_{40}$ depends on nucleation and is typically described by a sigmoidal curve.[1] First, we measured aggregation kinetics of $50 \mu_{\mathrm{M}} \mathrm{A} \beta_{40}$ in volumes of $100 \mu \mathrm{L}$ in well plates, where we observed a lag period of about $10 \mathrm{~h}$ before ThT fluorescence indicated $\mathrm{A} \beta_{40}$ aggregation (Figure 1d). In plugs with the fluorocarbon/water interface, the lag time of the aggregation reaction shortened to about $2 \mathrm{~h}$ (Figure 1e), correlated with the adsorption of the peptide to the fluorocarbon/water interface and also with the increased surface-to-volume ratio in $10 \mathrm{~nL}$ volumes. In contrast, in plugs with an $\mathrm{R}_{\mathrm{f}}-\mathrm{OEG}_{3} /$ water interface the lag time of aggregation increased to many days (Figure $1 \mathrm{f}$ ). After $250 \mathrm{~h}$, only 3 plugs out of 15 showed evidence of $A \beta_{40}$ aggregation. Even after 2 months, only 8 plugs out of 15 showed evidence of $A \beta_{40}$ aggregation (data not shown). Thus, control of the interfacial chemistry decreases the aggregation kinetics of $A \beta_{40}$ by at least an order of magnitude.

Next we tested whether this system could reliably handle aggregation experiments with small volumes by using CSF from a single mouse for a set of experiments. We compared the ability to inhibit $\mathrm{A} \beta_{40}$ aggregation for $\mathrm{CSF}(5 \mu \mathrm{L})$ from two mouse strains. In this comparison, we used a nontransgenic (wild-type, wt) mouse and a ceAPPswePS1 $\triangle$ E9/TTR-/-transgenic mouse 
that exhibits amyloid deposition throughout the cortex and hippocampus.[17] The ceAPPswePS1 $\triangle \mathrm{E} 9 / \mathrm{TTR}-/$ - mice lack the gene encoding transthyretin (TTR), a molecule that is enriched in CSF[18] and known to associate with $A \beta_{40}$ in both in vitro and in vivo settings. $[19,20]$ The inhibitory potency of CSF for each mouse was tested by generating plugs containing buffer, ThT, $\mathrm{A} \beta_{40}$, and different volumes of CSF. We described the amount of CSF in each plug in terms of "volume fraction" (the ratio of the volume of CSF in the plug to the total aqueous volume of the plug). Titrations were performed by changing the relative flow rates of all inlet streams[21] to generate plugs containing constant concentrations of ions and buffer, ThT, and $A \beta_{40}$, but different volume fractions of CSF (see Supporting Information for the titration algorithm). For each of the 15 different concentrations of CSF, 50 plugs were generated, giving 750 experiments for each sample of CSF. Aggregation of $A \beta_{40}$ was then monitored by the increase in ThT fluorescence. In contrast to the experiments with low ionic strength (Figure 1), the ionic strength of the buffer solution in CSF experiments was adjusted to accelerate aggregation and to resemble the ion composition of mouse CSF, which includes a high concentration of $\mathrm{Ca}^{2+}$ and $\mathrm{Mg}^{2+}$ ions. In accord with previous reports, the higher ionic strength led to a decrease in the lag time of aggregation of $A \beta_{40}$ [22] (see also Supporting Information).

Cerebrospinal fluid from the wild-type mouse was able to inhibit $\mathrm{A} \beta_{40}$ aggregation when added to plugs at volume fractions higher than 0.04 (Figure 2b). On the other hand, CSF from the ceAPPswePS $1 \triangle \mathrm{E} 9 / \mathrm{TTR}-/$ - mouse did not inhibit $\mathrm{A} \beta_{40}$ aggregation at volume fractions as high as 0.2 (Figure $2 \mathrm{c}$ ). These results agree with the difference in the inhibitory potency of human CSF from patients with and without Alzheimer's disease.[23] A qualitatively similar inhibitory effect on $A \beta_{40}$ aggregation was observed with recombinant TTR alone in plugs (Figure 2d), although this effect was substantially weaker. Concentrations of TTR of about $0.2-0.4 \mu_{\mathrm{M}}$, close to the physiological concentration of TTR in CSF,[9] were sufficient to inhibit aggregation. On the other hand, CSF from a wild-type mouse could be diluted 25-fold (to a water fraction of 0.04) without detectable loss of inhibitory activity. A dilution of TTR alone by less than 10 - fold (to $50 \mu_{\mathrm{M}}$ ) caused a substantial decrease in its ability to inhibit aggregation. This result implies that mouse TTR made, and possibly further modified, in vivo is considerably better at inhibiting aggregation than heterologously expressed human TTR, or it suggests that other factors in CSF can inhibit aggregation. The microfluidic system described here is attractive for performing further experiments to identify these putative factors in human CSF.

In conclusion, we used plug-based microfluidics and control of surface chemistry to miniaturize peptide aggregation experiments to nanoliter volumes. Although here we used the ThT assay to analyze aggregation in the micromolar range, plug-based microfluidics is compatible with other analytical methods potentially applicable to analysis in the nanomolar range, for example, mass spectrometry[24] or fluorescence correlation spectroscopy.[25] This approach could further advance in vitro aggregation biophysics, for example, time-controlled aging and nucleation-growth experiments[26] on amyloid peptides. Reducing "extrinsic" aggregation nucleated and driven by interfaces is attractive for understanding intrinsic aggregation mechanisms, and for finding molecules added in solution or attached to the interfaces[27] that can either accelerate or inhibit aggregation. Using plug-based microfluidics, we demonstrated that in aggregation assays the inhibitory activity of $5 \mu \mathrm{L}$ of CSF from a single mouse can be evaluated by setting up hundreds of experiments. In the area of Alzheimer's research, we are especially interested in the additional opportunities for evaluating potential diagnostic methods and for monitoring potential treatments. This approach may enable repeated analysis of CSF or brain interstitial fluid[11] from the same live animal, for example, by using the chemistrode.[25] 


\section{Supplementary Material}

Refer to Web version on PubMed Central for supplementary material.

\section{References}

1. Harper JD, Lansbury PT. Annu. Rev. Biochem 1997;66:385. [PubMed: 9242912]

2. Eisenberg D, Nelson R, Sawaya MR, Balbirnie M, Sambashivan S, Ivanova MI, Madsen AØ, Riekel C. Acc. Chem. Res 2006;39:568. [PubMed: 16981672]

3. Joachim CL, Mori H, Selkoe DJ. Nature 1989;341:226. [PubMed: 2528696]

4. Schladitz C, Vieira EP, Hermel H, Möhwald H. Biophys. J 1999;77:3305. [PubMed: 10585952]

5. Giacomelli CE, Norde W. Macromol. Biosci 2005;5:401. [PubMed: 15889393]

6. Terzi E, Holzemann G, Seelig J. J. Mol. Biol 1995;252:633. [PubMed: 7563079]

7. Hofrichter J, Ross PD, Eaton WA. Proc. Natl. Acad. Sci. USA 1974;71:4864. [PubMed: 4531026]

8. Kanekiyo T, Ban T, Aritake K, Huang ZL, Qu WM, Okazaki I, Mohri I, Murayama S, Ozono K, Taniike M, Goto Y, Urade Y. Proc. Natl. Acad. Sci. USA 2007;104:6412. [PubMed: 17404210]

9. Serot JM, Christmann D, Dubost T, Couturier M. J. Neurol. Neurosurg. Psychiatry 1997;63:506. [PubMed: 9343132]

10. Ma J, Yee A, Brewer HB, Das S, Potter H. Nature 1994;372:92. [PubMed: 7969426]

11. Brody DL, Magnoni S, Schwetye KE, Spinner ML, Esparza TJ, Stocchetti N, Zipfel GJ, Holtzman DM. Science 2008;321:1221. [PubMed: 18755980]

12. Song H, Chen DL, Ismagilov RF. Angew. Chem 2006;118:7494.Angew. Chem. Int. Ed 2006;45:7336.

13. McDonald JC, Whitesides GM. Acc. Chem. Res 2002;35:491. [PubMed: 12118988]

14. Li L, Mustafi D, Fu Q, Tereshko V, Chen DL, Tice JD, Ismagilov RF. Proc. Natl. Acad. Sci 2006;103:19243. [PubMed: 17159147]

15. Roach LS, Song H, Ismagilov RF. Anal. Chem 2005;77:785. [PubMed: 15679345]

16. LeVine H. Methods Enzymol 1999;309:274. [PubMed: 10507030]

17. Choi S, Leight S, Lee V, Li T, Wong P, Johnson J, Saraiva M, Sisodia S. J. Neurosci 2007;27:7006. [PubMed: 17596449]

18. Herbert J, Wilcox JN, Pham KT, Fremeau RT Jr, Zeviani M, Dwork A, Soprano DR, Makover A, Goodman DS, Zimmerman EA, Roberts JL, Schon EA. Neurology 1986;36:900. [PubMed: 3714052]

19. Schwarzman AL, Gregori L, Vitek MP, Lyubski S, Strittmatter WJ, Enghilde JJ, Bhasin R, Silverman J, Weisgraber KH, Coyle PK. Proc. Natl. Acad. Sci. USA 1994;91:8368. [PubMed: 8078889]

20. Link CD. Proc. Natl. Acad. Sci. USA 1995;92:9368. [PubMed: 7568134]

21. Song H, Ismagilov RF. J. Am. Chem. Soc 2003;125:14613. [PubMed: 14624612]

22. Sengupta P, Garai K, Sahoo B, Shi Y, Callaway DJ, Maiti S. Biochemistry 2003;42:10506. [PubMed: 12950178]

23. Ono K, Noguchi M, Matsumoto Y, Yanase D, Iwasa K, Naiki H, Yamada M. Neurobiol. Dis 2005;20:233. [PubMed: 16242632]

24. Hatakeyama T, Chen DL, Ismagilov RF. J. Am. Chem. Soc 2006;128:2518. [PubMed: 16492019]

25. Chen D, Du W, Liu Y, Liu W, Kuznetsov A, Mendez FE, Philipson LH, Ismagilov RF. Proc. Natl. Acad. Sci. USA 2008;105:16843. [PubMed: 18974218]

26. Gerdts CJ, Tereshko V, Yadav MK, Dementieva I, Collart F, Joachimiak A, Stevens RC, Kuhn P, Kossiakoff A, Ismagilov RF. Angew. Chem 2006;118:8340.Angew. Chem. Int. Ed 2006;45:8156.

27. Kreutz JE, Li L, Roach LS, Hatakeyama T, Ismagilov RF. J. Am. Chem. Soc. submitted 
a)

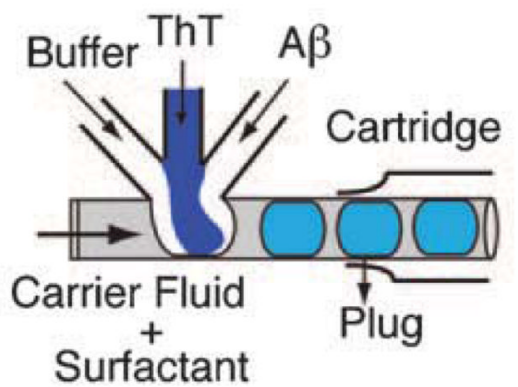

b)

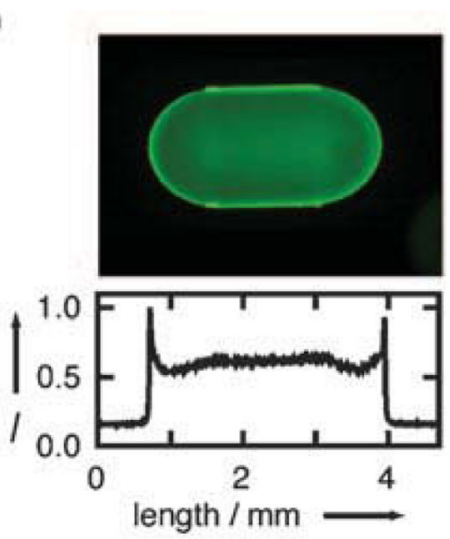

c)

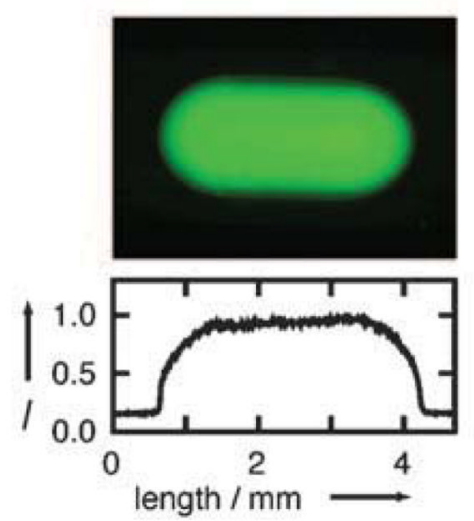

d)

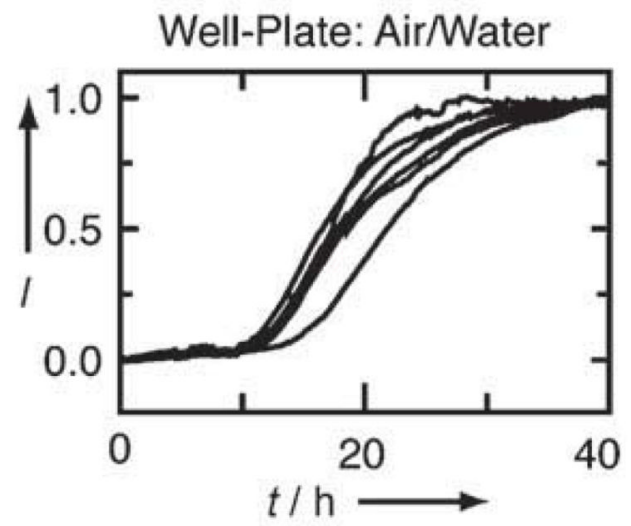

e)

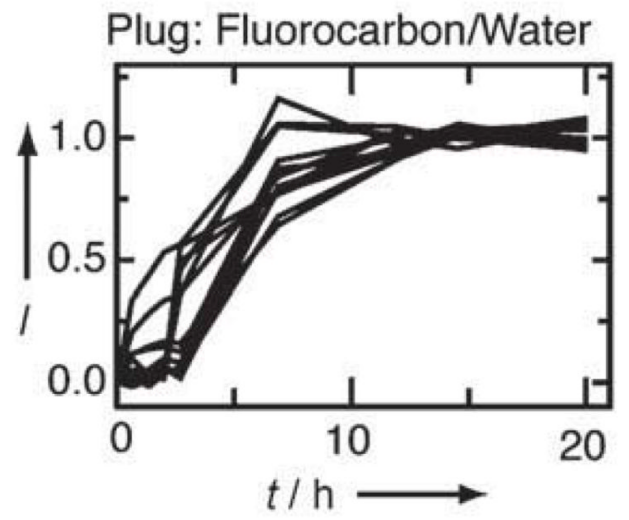

f)

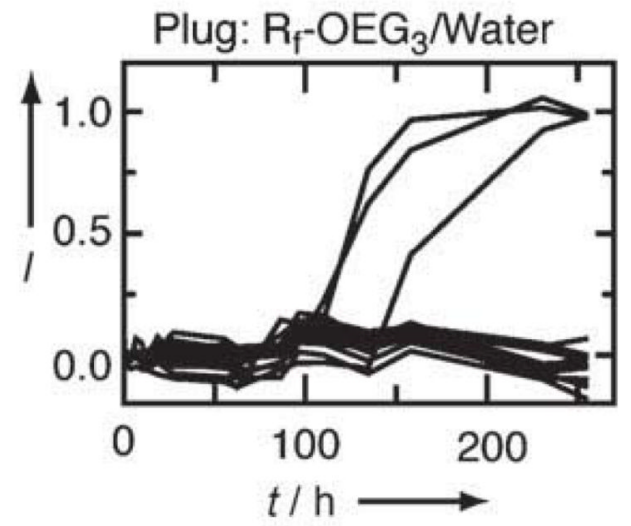

Figure 1.

Encapsulation and aggregation of $A \beta_{40}$ in plugs with controlled interfaces compared with plugs without interfacial control and with a well plate. a) Schematic of the microfluidic device. Fluorescence images of $22 \mu_{\mathrm{M}}$ HiLyte-488-labeled $\mathrm{A} \beta_{40}$ in plugs with b) fluorocarbon/water and c) $\mathrm{R}_{\mathrm{f}}-\mathrm{OEG}_{3} /$ water interface. Corresponding line scans of the plugs are given below each image. Aggregation kinetics of $50 \mu_{\mathrm{M}} \mathrm{A} \beta_{40}$ in $50 \mu_{\mathrm{M}}$ Tris buffer at $37^{\circ} \mathrm{C}$ measured by ThT fluorescence in d) a well plate with an air/water interface, e) plugs with a fluorocarbon/water interface, and f) plugs with an $\mathrm{R}_{\mathrm{f}}-\mathrm{OEG}_{3} /$ water interface. Note the difference in timescales. 
a)

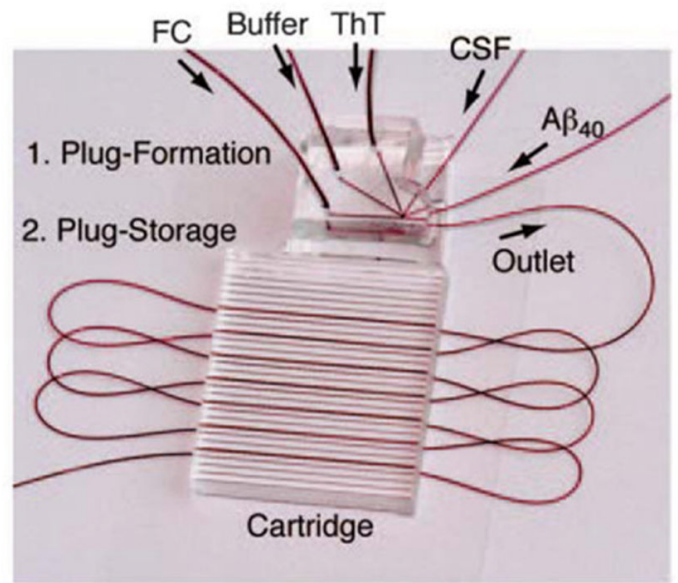

b)

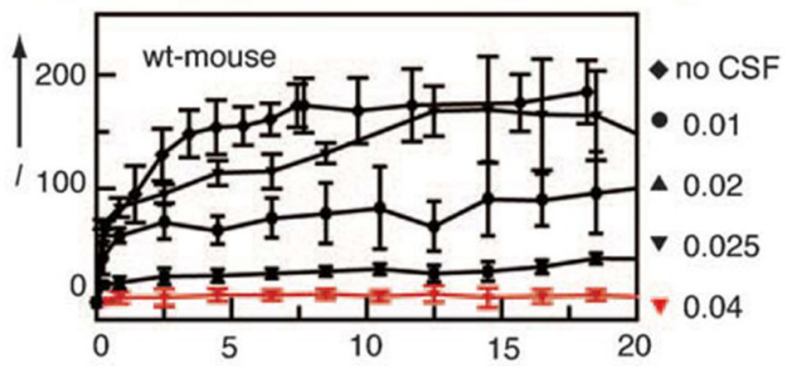

c)

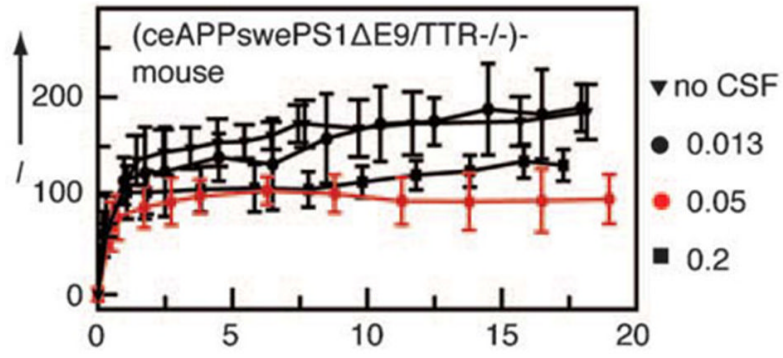

d)

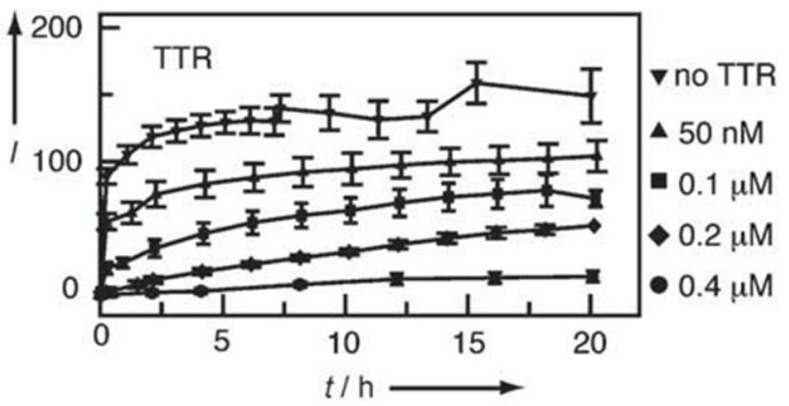

Figure 2.

CSF titration experiments. a) Microfluidic device designed for performing 250 aggregation trials of $A \beta_{40}$ with different volume fractions of CSF or concentrations of protein. Aggregation kinetics of $50 \mu_{\mathrm{M}} \mathrm{A} \beta_{40}$ on addition of various volume fractions of CSF b) from wild-type mouse and c) from a mouse which is a model for Alzheimer's disease (ceAPPswePS1 $\Delta$ E9/TTR-/-). The volume fraction is defined as the ratio of volume of CSF to total aqueous plug volume and is shown to the right of the graphs. d) Aggregation kinetics of $50 \mu_{\mathrm{M}} \mathrm{A} \beta_{40}$ on addition of various concentrations of TTR. Aggregation was measured by ThT fluorescence, where $I$ is the fluorescence intensity of ThT normalized to the fluorescence intensity at $t=0$. Each data point is averaged over 15 plugs, and the error bars are the standard deviations. 